\title{
KEMAMPUAN PRAKTIK KERJA INDUSTRI DAN STATUS SOSIAL EKONOMI ORANG TUA DENGAN MOTIVASI BEKERJA SISWA KELAS XII TIPTL (Studi Kasus di SMK Negeri 5 Jakarta) \\ ${ }^{1}$ Diyah Ayu Mustika, ${ }^{2}$ Daryanto, ${ }^{3}$ Faried Wadjidi \\ ${ }^{1,2.3}$ Pendidikan Teknik Elektro, Universitas Negeri Jakarta \\ ${ }^{1}$ Email : mustikaayudiyah @gmail.com
}

\begin{abstract}
Research aims to determine relationship between the ability of industrial work practice and parents' social economic status with work motivation of students class XII TIPTL at SMK Negeri 5 Jakarta.

This research starting from June untill October 2017. The method that use in this research is descriptive correlational with survei. Population of this research are 85 students of class XII TIPTL at SMKN 5 Jakarta, and 68 students are the sample of this research using sampling probability technique which is proportionate stratified random sampling. Data result of this research analyzed with analysis prerequisite test by using normality test, regression test, regression significance test and regression linearity test at significant level $\alpha=$ 0,05. And analysis tes with correlation coefficient hypothesis test at significant level $\alpha=0,05$.

The result of this research shows that the existence of a significant relation existsbetween the industrial work practices with the motivation to work can be seen from $r_{\text {count }}=0,611>r_{\text {table }}=0,239$ mean while the determination to $R^{2}=37,35 \%$ with an equation regression $\hat{Y}=25,01+0,841 X_{1}$. Research also suggests that the relationship a significant relation exists between the parents social economic status with motivation to work can be seen from $r_{\text {count }}=0,7201>r_{\text {table }}=0,239$ mean while the determination to $R^{2}=51,81 \%$ with an equation regression $\hat{Y}=62,21+0,484 X_{2}$. In addition the research indicated a significant relation exists between the work practices industry and the parents social economic status with the motivation to work with regression equation $\hat{Y}=36,881+0,402 X_{1}+0,370 X_{2}$ and the result of analysis of data is collected $F_{\text {count }}$ adalah 43,96 and $F_{\text {table }}=3,14$, so that $F_{\text {count }}>F_{\text {table. }}$. This suggests that a hypothesis that indicated a significant relation exists between the work practices industry and the parents social economic statusreceived with the motivation to work. Meanwhile the determination to $R^{2}$ is $57,5 \%$ while the rest $42,5 \%$ influenced by other factors not researched.
\end{abstract}

Keywords : Industrial work practice, parents' social economic status, work motivation

\begin{abstract}
Abstrak
Penelitian ini bertujuan untuk mengetahui hubungan antara kemampuan praktik kerja industri dan status sosial ekonomi orang tua dengan motivasi bekerja pada Siswa kelas XII TIPTL di SMK Negeri 5 Jakarta.

Penelitian ini dilakukan terhitung mulai pada bulan Juni sampai dengan bulan Oktober 2017. Untuk metode yang digunakan didalam penelitian ini adalah penelitian deskriptif korelasi dengan survey. Populasi penelitian ini adalah siswa kelas XII TIPTL di SMKN 5 Jakarta yang berjumlah 85 siswa, dan sampel yang diambil sebanyak 68 siswa dengan menggunakan teknik probabilitas sampling, yaitu proportionate stratified random sampling. Data hasil penelitian dianalisis melalui uji prasyarat analisis dengan menggunakan uji normalitas, uji regresi, uji keberartian regresi dan uji kelinieritasan regresi pada taraf signifikan $\alpha=0,05$. Dan uji analisis dengan uji hipotesis koefisien korelasi pada taraf signifikan $\alpha=0,05$.

Hasil dari penelitian ini menunjukan bahwa adanya hubungan yang positif dan signifikan antara kemampuan praktik kerja industri dengan motivasi bekerja yang ditunjukan dengan $r_{\text {hitung }}=0,611>r_{\text {tabel }}=0,239$ sementara itu koefisien determinasi untuk $\mathrm{R}^{2}=37,35 \%$. Penelitian pula menunjukan bahwa adanya hubungan yang positif dan signifikan antara status social ekonomi orang tua dengan motivasi bekerja yang ditunjukan dengan $\mathrm{r}_{\text {hitung }}=0,720>\mathrm{r}_{\text {tabel }}=0,239$, sementara itu koefisien determinasi untuk $\mathrm{R}^{2}=51,81 \%$. Selain itu hasil penelitian menunjukan adanya hubungan yang signifikan antara kemampuan praktik kerja industri dan status sosial ekonomi orang tua dengan motivasi bekerja dengan persamaan regresi $\hat{Y}=36,881+0,402 X_{1}+0,370 X_{2}$, dan hasil dari analisa data diperolehF $F_{\text {hitung }}=43,96>\mathrm{F}_{\text {tabel }}=3,14$. Hal ini menunjukan bahwa hipotesis yang menunjukan adanya hubungan yang positif dan signifikan antara kemampuan praktik kerja industri dan status sosial ekonomi orang tua dengan motivasi bekerja diterima. Sementara itu koefisien determinasi untuk $\mathrm{R}^{2}$ adalah $57,5 \%$ sedangkan sisanya $42,5 \%$ dipengaruhi oleh faktor lain yang tidak diteliti.
\end{abstract}

Kata Kunci:Praktik kerja industri, status sosial ekonomi orang tua, motivasi bekerja

\section{PENDAHULUAN}

Dalam penelitian Firmansyah Aditya (2013:20) yang berjudul “Analisis Pelaksanaan
Praktek Kerja Industri (Prakerin) pada Program Keahlian Administrasi Perkantoran Kelas XI SMKN 4 Surabaya" menyatakan suatu bentuk 
penyelenggaraan pendidikan keahlian kejujuran yang memadukan secara utuh dan terintergrasi program penguasaan keahlian yang diperoleh melalui kegiatan bekerja langsung dilapangan. Kegiatan prakerin harus ada kesepakatan antara pihak sekolah menengah kejujuran dengan industri sebagai intitusi pasangan mulai dari tahap perencanaan, pelaksanaan hingga tahap evaluasi dan sertifikasi.

Praktek kerja industri (Prakerin) merupakan salah satu bagian dari kegiatan yang diadakan di SMK Negeri 5 Jakarta dan praktek kerja industri memang wajib dilakukan oleh SMK Negeri maupun SMK Swasta, karena praktek industri sangat baik untuk mendukung atau menyalurkan bakat yang dimiliki siswa dan sebagai tempat belajar sebelum mereka terjun langsung ke dunia usaha atau dunia industri setelah lulus dari SMK.

Diadakannya Prakerin di SMK terutama pada program keahlian TIPTL (teknik instalasi pemanfaatan tenaga listrik) ditujukan agar peserta didik memiliki kemampuan lebih terkait bidang ketenaga listrikan.

Tak hanya kemampuan prakerin namun juga status sosial ekonomi orang tua peserta didik pun sangat berpengaruh dalam motivasi anak. Status sosial ekonomi adalah kedudukan atau posisi seseorang dalam kelompok masyarakat yang ditentukan oleh jenis aktivitas ekonomi, pendidikan serta pendapatan. Stuasi sosial ekonomi setiap peserta didik pasti berbeda, tergolong dari tingkat sosial ekonomi yang tinggi, menengah dan rendah. Kondisi ini pun akan sangat berpengaruh pada motivasi yang dimiliki peserta didik untuk bekerja. Beberapa diantaranya jika status sosial ekonominya tinggi besar kemungkinan peserta didik akan memiliki motivasi untuk bekerja, karena melihat kondisi orang tua dan terdorong untuk bekerja. Berbeda dengan peserta didik yang memiliki kondisi sosial rata - rata menengah ke bawah, besar kemungkinan peserta didik akan memiliki motivasi bekerja yang menengah kebawah dikarenakan ketidak pahaman orang tua akan terkait pendidikan didunia kerja.

Dalam penelitian Destiny Rastanura Sitinjak (2016:11) yang berjudul "Hubungan Antara Status sosial eknomi Dengan Motivasi belajar Pada siswa SMK N 44 Jakarta"mengatakan bahwa status sosialekonomi merupakan posisi yang ditempati individu atau keluarga yang berkenaan dengan ukuran rata-rata yang umum berlaku tentang kepemilikankultural, pendapatan efektif, pemilikan barang dan partisipasi dalam aktifitas kelompok dari komunitasnya.Sehingga dapat disimpulkan bahwa status sosial ekonomi adalah tinggi rendahnya prestise yang dimiliki seseorang berdasarkan kedudukan yang dipegangnya dalam suatu masyarakat berdasarkan pada pekerjaan untuk memenuhi kebutuhannya atau keadaan yang menggambarkan posisi atau kedudukan suatu keluarga masyarakat berdasarkan kepemilikanmateri.

Dengan adanya status sosial ekonomi yang menggambarkan kedudukan dan kebutuhan baik jasmani maupun rohani yang harus dipenuhi. Seorang peserta didik akan sadar bahwa ia harus mandiri dan memenuhi kebutuhan fisiologisnya tanpa harus bergantung kepada orang tua lagi setelah ia lulus dari SMK, terlebih jika orang tuanya memiliki keterbatasan ekonomi. Selain itu, peserta didik juga akan merasa bangga memiliki sebuah pekerjaan setelah lulus daripada menganggur. Rasa bangga ini merupakan salah satu contoh bahwa seorang peserta didik memiliki kebutuhan penghormatan atas dirinya. Dorongan dan desakan dari lingkungan sekitarnya baik dari lingkungan sekolah, lingkungan keluarga, maupun lingkungan masyarakat juga akan memberikan motivasi kepada peserta didik untuk memasuki dunia kerja.

Tidak hanya kemampuan Prakerin yang harus dimiliki peserta didik dan Status sosial ekonomi peserta didik, namun peserta didik pun harus termotivasi dengan adanya praktek kerja industri tersebut untuk dapat bekrja langsung di industri. Dimana motivasi bekerja di Industri adalah sesuatu yang menimbulkan semangat atau dorongan individu untuk memasuki dunia kerja di industri, baik berasal dari dalam diri sendiri maupun dari luar dirinya.

Disambung oleh penelitian Fredi Prima Sakti (2014:22) yang berjudul "Pengaruh Penguasaan Kompetensi Keahlian dan Informasi Dunia Kerja Terhadap Minat Bekerja Siswa Kelas XI Program Keahlian Teknik Instalasi Tenaga Listrik di SMKN 2 Yogyakarta" mengatakan bahwa timbulnya minat dipengaruhi oleh beberapa faktor yang terbagi menjadi dua, yaitu faktor intrinsik dan faktor ekstrinsik. Faktor intrinsik meliputi 
adanya kebutuhan akan pendapatan, nilai-nilai pribadi, konsep diri, harga diri, persepsi dan perasaan senang. Faktor ekstrinsik yang mempengaruhi minat yaitu lingkungan keluarga, lingkungan masyarakat, peluang, dan pendidikan. Siswa yang melihat pekerjaan bidang ketenagalistrikan sebagai suatu obyek yang menyenangkan, menarik perhatian dan dianggap bermanfaat bagi diri nya serta ada kemungkinan untuk melaksanakannya berarti ia berminat pada pekerjaan tersebut, sehingga ia akan cenderung lebih aktif menaruh perhatian pada obyek tersebut.

Dari uraian latar belakang masalah tersebut di atas, penulis menemukan beberapa jurnal hasil penelitian yang telah lalu menyangkut masingmasing variabel. Karena tidak adanya penelitian yang menghubungkan semua variabel yang diteliti oleh penulis, maka penulis dalam penelitian ini mengambil judul "Hubungan antara Kemampuan Pratek Kerja Industri dan Status Sosial Ekonomi Orang Tua dengan Motivasi Bekerja Siswa kelas XII SMKN 5 Jakarta”.

\section{METODE}

Metode penelitian yang digunakan dalam penelitian ini adalah penelitian deskriptif korelasional dengan survey.

Dalam penelitian ini, yang termasuk kedalam populasi adalah siswa kelas XII SMKN 5 Jakarta Paket Keahlian Teknik Instalasi Pemanfaatan Tenaga Listrik yang berjumlah 85 siswa. Dan pnentuan jumlah sampel dari populasi dkembangkan dari rumus Isaac dan Michael untuk tingkat kesalahan $5 \% \alpha=0,05$. Dengan rumus berikut:

$$
s=\frac{\lambda^{2} \cdot N \cdot P \cdot Q}{\lambda^{2}(N-1)+\lambda^{2} \cdot P \cdot Q}
$$

Dari populais 85 siswa didapat sampel sejumlah 68 siswa.

Sebelum peneliti melakukan pengujian hipotesis, dilakukan uji prasyarat hipotesis statistik yaitu uji normalitas dengan menggunakan uji Lilifors dan uji regresi linieritas.

\section{Uji normalitas}

Uji Normalitas dilakukan untuk mengetahui apakah data yang diambil berasal dari populasi yang berdistribusi normal atau tidak. (Juliansyah, 2010:174) Pengujian normalitas ini menggunakan uji Liliefors dengan taraf $\alpha=$ 0,05 .

2. Uji Regresi Berganda

Untuk pengujian regresi berganda ini adalah analisis tentang antara satu dependentvariable dengan dua atau lebih independen variable.rumusy $=a+b X+c Z$

3. Uji linearitas regresi

Tujuan uji linieritas regresi ini adalah untuk mengetahui apakah antara variable bebas dengan variabel terikat memiliki hubungan yang linier atau tidak. Pengujian ini menggunakan uji $\mathrm{F}$ dengan taraf $\alpha=0,05$.

Sedangkan untuk uji hipotesis dengan menggunakan pengujian :

1. Uji koefisien korelasi

Untuk pengujian hipotesis penelitian dalam penelitian ini diuji menggunakan uji statistik product moment untuk melihat hubungan antara variabel $\mathrm{x}$ dan variabel y dengan taraf $\alpha$ $=0,05$.

2. Signifikansi korelasi (Uji t)

Uji t merupakan uji yang digunakan untuk mengetahui pengaruh variabel independen terhadap variabel dependen, apakah pengaruhnya signifikan atau tidak.

3. Uji Koefisien Korelasi Berganda

Uji Statistik Koefisien Korelasi Berganda digunakan untuk menguji signifikan atau tidaknya hubungan lebih dari dua variabel dengan menggunakan uji $\mathrm{F}$.

\section{HASIL DAN PEMBAHASAN}

\section{Hasil Pengujian Persyaratan Analisis}

1. Hasil Pengujian Normalitas

Dari hasil perhitungan normalitas pada variabel motivasi bekerja diperoleh nilai $\mathrm{L}_{\text {hitung }}=0,066$, sedangkan $\mathrm{L}_{\text {tabel }(0,05)}=0,107$. Jadi $\mathrm{L}_{\text {hitung }}<\mathrm{L}_{\text {tabel, }}$ yakni $0,066<0,107$, maka $\mathrm{H}_{\mathrm{o}}$ diterima. disimpulkanbahwa variabel motivasi bekerja pada siswa berdistribusi normal.

Dari hasil variabel Kemampuan Prakerin diperoleh hasil perhitungan nilai $\mathrm{L}_{\text {hitung }}=0,062$, sedangkan $\mathrm{L}_{\text {tabel }(0,05)}=0,107$. Jadi $\mathrm{L}_{\text {hitung }}<\mathrm{L}_{\text {tabel }}$, yakni $0,062<0,107$, maka $\mathrm{H}_{\mathrm{o}}$ diterima. Maka,disimpulkan data variabel kemampuan prakerin berdistribusi normal.

Selanjutnya dari variabel Status Sosial Ekonomi Orang Tua diperoleh dengan nilai $\mathrm{L}_{\text {hitung }}=0,059$, sedangkan $\mathrm{L}_{\text {tabel }(0,05)}=0,107$. 
Jadi $\mathrm{L}_{\text {hitung }}<\mathrm{L}_{\text {tabel}}$, yakni $0,059<0,107$, maka $\mathrm{H}_{\mathrm{o}}$ diterima. Maka dari itu, disimpulkan data variabel Status Sosial Ekonomi Orang Tua berdistribusi normal.

2. Hasil Pengujian Regresi linier

a. Hubungan antara Kemampuan Prakerin dengan Motivasi Bekerja.

Hasil perhitungan regresi sederhana dari hubungan Kemampuan Prakerin dengan Motivasi Bekerja adalah $\hat{y}=25,01+0,841 X_{1}$.

Tabel 1. Tabel Anava Untuk Uji Keberartian Dan

\begin{tabular}{|c|c|c|c|c|c|}
\hline Sumber & dk & Jumlah & $\begin{array}{c}\text { Rata-rata } \\
\text { Jumlah }\end{array}$ & F $_{\text {hitung }}$ & $F_{\text {tabel }}$ \\
\hline Varians & & Kuadrat (JK) & $\underset{\text { Kuadrat }}{\text { (RJK) }}$ & & \\
\hline Total & 68 & 592811 & & & \\
\hline Regresi (a) & 1 & 590552,485 & & & \\
\hline Regresi (b/a) & 1 & 843,594 & 843,594 & 39,350 & 3,986 \\
\hline Residu & 66 & 1414,921 & 21,438 & & \\
\hline Tuna Cocok & 17 & 363,811 & 21,401 & 0,998 & 1,836 \\
\hline $\begin{array}{l}\text { Galat } \\
\text { Kekeliruan }\end{array}$ & 49 & 1051,110 & 21,451 & & \\
\hline
\end{tabular}

b. Hubungan antara Status Sosial Ekonomi Orang Tua dengan Motivasi Bekerja

Hasil regresi sederhana dari hubungan Status Sosial Ekonomi Orang Tua dengan Motivasi Bekerja adalah $\hat{y}=62,21+0,484 X_{2}$

Tabel 2. Tabel Anava Untuk Uji Keberartian Dan

\begin{tabular}{|c|c|c|c|c|c|}
\hline Sumber & dk & Jumlah & $\begin{array}{c}\text { Rata- } \\
\text { rata } \\
\text { Jumlah }\end{array}$ & $\mathbf{F}_{\text {hitung }}$ & $\mathbf{F}_{\text {tabel }}$ \\
\hline Varians & & $\begin{array}{c}\text { Kuadrat } \\
\text { (JK) }\end{array}$ & $\begin{array}{c}\text { Kuadrat } \\
\text { (RJK) }\end{array}$ & & \\
\hline Total & 68 & 592811 & & & \\
\hline Regresi (a) & 1 & 590552,49 & & & \\
\hline $\begin{array}{l}\text { Regresi } \\
\text { (b/a) }\end{array}$ & 1 & 1170,20 & 1170,20 & 70,97 & 4,04 \\
\hline Residu & 66 & 1088,31 & 16,49 & & \\
\hline $\begin{array}{l}\text { Tuna } \\
\text { Cocok }\end{array}$ & 32 & 559,39 & 17,48 & 1,12 & 1,78 \\
\hline $\begin{array}{l}\text { Galat } \\
\text { Kekeliruan }\end{array}$ & 34 & 528,92 & 15,56 & & \\
\hline
\end{tabular}

c. Hubungan antara Kemampuan Prakerin dan Status Sosial Ekonomi Orang Tua dengan Motivasi Bekerja

Dari hasil perhitungan regresi berganda didapat $\hat{Y}=36,881+0,402 X_{1}+0,370 X_{2}$

Tabel 3. Tabel Anava Untuk Uji Keberartian Dan

\begin{tabular}{|c|c|c|c|c|c|c|}
\hline \multirow{3}{*}{$\begin{array}{l}\text { Sumber } \\
\text { Varians }\end{array}$} & \multirow{3}{*}{ Dk } & \multirow{3}{*}{$\begin{array}{c}\text { Jumlah } \\
\text { Kuadra } \\
\text { t (JK) }\end{array}$} & \multirow{3}{*}{$\begin{array}{c}\text { Rata-rata } \\
\text { Jumlah } \\
\text { Kuadrat } \\
\text { (RJK) }\end{array}$} & \multirow{3}{*}{$\mathbf{F}_{\text {hitung }}$} & \multirow{2}{*}{\multicolumn{2}{|c|}{$\mathbf{F}_{\text {tabel }}$}} \\
\hline & & & & & & \\
\hline & & & & & 0,05 & 0,01 \\
\hline Total & 68 & 592811 & & & & \\
\hline Regresi & 2 & 1298,53 & 649,27 & 43,96 & 3,14 & 4,95 \\
\hline Residu & 65 & 959,98 & 14,77 & & & \\
\hline
\end{tabular}

\section{Uji Hipotesis}

1. Hubungan antara Kemampuan Prakerin dengan Motivasi Bekerja

Tabel 4. Koefisien Korelasi antara Kemampuan Prakerin dan Motivasi Bekerja

\begin{tabular}{cccccc}
\hline $\begin{array}{c}\mathbf{d f}= \\
\mathbf{N}-\mathbf{2}\end{array}$ & $\mathbf{r}_{\mathbf{y 1}}$ & $\mathbf{r}_{\text {tabel(0,05) }}$ & $\mathbf{r}_{\mathbf{y 1}}{ }^{2}$ & $\mathbf{t}_{\text {hitung }}$ & $\mathbf{t}_{\text {tabel(0,05) }}$ \\
\hline $\mathbf{6 6}$ & 0,611 & 0,239 & 0,3735 & 6,27 & 1,68 \\
\hline
\end{tabular}

Maka disimpulkan bahwa $r_{\text {hitung }}>\mathrm{r}_{\text {tabel }}$ yang berarti terdapat adanya hubungan. Dengan demikian terdapat $t_{\text {hitung }}>t_{\text {tabel }}$, yang berarti terdapat hubungan yang signifikan antara variabel Kemampuan Prakerin $\left(\mathrm{X}_{1}\right)$ dengan variabel Motivasi Bekerja(Y). Dan dari hasil tersebut diinterpretasikan bahwa koefisien determinasi hubungan antara kemampuan prakerin dengan Motivasi Bekerja sebesar $37,35 \%$.

2. Hubungan antara Status Sosial Ekonomi Orang Tua dengan Motivasi Bekerja

Tabel 5. Koefisien Korelasi antara Status Sosial Ekonomi Orang Tua dan Motivasi Bekerja

\begin{tabular}{cccccc}
\hline $\mathbf{d f}=\mathbf{N}-\mathbf{2}$ & $\mathbf{r}_{\mathbf{y} 2}$ & $\mathbf{r}_{\text {tabel(0,05) }}$ & $\mathbf{r}_{\mathbf{y 2}}{ }^{2}$ & $\mathbf{t}_{\text {hitung }}$ & $\mathbf{t}_{\text {tabel(0,05) }}$ \\
\hline $\mathbf{6 6}$ & 0,720 & 0,239 & 0,5181 & 8,42 & 1,68 \\
\hline
\end{tabular}

Maka disimpulkan bahwa $\mathrm{r}_{\text {hitung }}>\mathrm{r}_{\text {tabelyang }}$ berarti terdapat adanya hubungan positif.Dengan demikian terdapat $t_{\text {hitung }}>t_{\text {tabel }}$, yang berarti terdapat hubungan yang signifikan antaravariabel Status Sosial Ekonomi Orang Tua $\left(\mathrm{X}_{2}\right)$ dengan variabel Motivasi Bekerja(Y). Dan dari hasil tersebut diinterpretasikan bahwa koefisien determinasi hubungan antara Status Sosial Ekonomi Orang Tua dengan Motivasi Bekerja sebesar 51,81\%.

3. Hubungan antara Kemampuan Prakerin dan Status Sosial Ekonomi Orang Tua dengan Motivasi Bekerja

Tabel 6. Koefisien Korelasi Ganda Kemampuan Prakerin dan Status Sosial Ekonomi Orang Tua dengan Motivasi Bekerja

\begin{tabular}{cccccc}
\hline $\mathbf{d f}=\mathbf{N}-\mathbf{2}$ & $\mathbf{r}_{\mathbf{y 1 2}}$ & $\mathbf{r}_{\text {tabel(0,05) }}$ & $\mathbf{r}_{\mathbf{y 1 2}} \mathbf{2}^{2}$ & $\mathbf{F}_{\text {hitumg }}$ & $\mathbf{F}_{\text {tabel(0,05) }}$ \\
\hline $\mathbf{6 6}$ & 0,758 & 0,239 & 0,575 & 43,96 & 3,14 \\
\hline
\end{tabular}

Disimpulkan dari tabel $6 \mathrm{r}_{\text {hitung }}>\mathrm{r}_{\text {tabel }}$ yang berarti terdapat adanya hubungan positif. Dengan demikian terhitung $F_{h}>F_{t}=$ Ho ditolak : koefisien korelasi ganda signifikan dan terdapat hubungan yang signifikan antaravariabel Kemampuan Prakerin $\left(\mathrm{X}_{1}\right)$ danStatus Sosial Ekonomi Orang Tua $\left(\mathrm{X}_{2}\right)$ dengan variabel Motivasi $\operatorname{Bekerja}(\mathrm{Y})$. Koefisien determinasi hubungan antara 
kemampuan prakerin dan Status Sosial Ekonomi Orang Tua dengan Motivasi Bekerja sebesar 57,5\%.

\section{Pembahasan}

Dalam penelitian yang telah dilakukan oleh peneliti untuk mencari kebenaran apakah adanya hubungan antara kemampuan prakerin dan status sosial ekonomi orang tua dengan motivasi bekerja siswa kelas XII TIPTL di SMKN 5 Jakarta, maka disajikan dalam pembahasan hasil penelitian sebagai berikut:

1. Hubungan antara antara kemampuan prakerin dan motivasi bekerja siswa kelas XII TIPTL di SMKN5 Jakarta

Berdasarkan hasil persamaan regresi linier yang didapat dari hubungan antar kemampuan prakerin dan motivasi bekerja adalah $\hat{\mathrm{y}}=25,01+0,841 \mathrm{X}_{1}$, dimana koefisien regresi sebesar 0,841 dan konstanta sebesar 25,01. Arti dari angka tersebut adalah nilai koefisien regresi variabel kemampuan praktik kerja industi bernilai positif, yaitu sebesar 0,841 . Diartikan bahwa setiap peningkatan satu skor untuk kemampuan prakerin, maka akan meningkat pula motivasi bekerja sebesar 0,841 skor.

Pada analisis koefisien korelasi antara kemampuan prakerin dengan motivasi bekerja didapat $r_{\mathrm{y} 1}=0,611$ dan $\mathrm{r}_{\text {tabel }}=0,239$ maka $r_{\text {hitung }}>r_{\text {tabelyang }}$ berarti terdapat adanya hubungan positif, serta thitung $=6,27$ dan $\mathrm{t}_{\text {tabel }}=1,68, \mathrm{t}_{\text {hitung }}>\mathrm{t}_{\text {tabel }}$ yang berarti terdapat hubungan yang signifikan. Dan dari perhitungan diperoleh koefisien determinasi sebesar $37,35 \%$, sehingga dapat disimpulkan bawha variabel motivasi bekerja (Y) ditentukan sebesar $37,35 \%$ oleh variabel kemampuan prakerin $\left(\mathrm{X}_{1}\right)$.

2. Hubungan antara status sosial ekonomi orang tua dengan motivasi bekerja siswa kelas XII TIPTL di SMKN5 Jakarta.

Berdasarkan hasil persamaan regresi linier dari hubungan antar status sosial ekonomi orang tua dan motivasi bekerja didapatlah $\hat{y}=62,21+0,484 X_{2}$, dimana koefisien regresi sebesar 0,484 dan konstanta sebesar 62,21. Dapat diartikan bahwa nilai koefisien regresi variabel status sosial ekonomi orang tua bernilai positif, yaitu sebesar 0,484. Diartikan bahwa setiap peningkatan satu skor untuk status sosial ekonomi orang tua, maka akan meningkat nya motivasi bekerja sebesar 0,484 skor.

Maka berdasarkan analisis bahwa koefisien korelasi status sosial ekonomi orang tua dengan motivasi bekerja disimpulkan didapat hasil $r_{y 1}=0,720$ dan $r_{\text {tabel }}=0,239$ maka $r_{\text {hitung }}>r_{\text {tabelyang }}$ berarti terdapat adanya hubungan positif, sertat $t_{\text {itung }}=8,42$ dan $\mathrm{t}_{\text {tabel }}=1,68$ maka $\mathrm{t}_{\text {hitung }}>\mathrm{t}_{\text {tabel, }}$ yang berarti terdapat hubungan yang signifikan antaravariabel Status Sosial Ekonomi Orang Tua $\left(\mathrm{X}_{2}\right)$ dengan variabel Motivasi Bekerja(Y). Selain itu dari perhitungan diperoleh koefisien determinasi sebesar $51,81 \%$, sehingga dapat disimpulkan bawha variabel motivasi bekerja (Y) ditentukan sebesar $51,81 \%$ oleh variabel status sosial ekonomi orang tua $\left(\mathrm{X}_{2}\right)$.

Hal ini menunjukan status sosial ekonomi orang tua dapat mempengaruhi motivasi bekerja pada siswa, dengan status sosial ekonomi orang tua yang rendah dan kecakapan akademis orang tua pun digolongkan kedalam golongan rendah didalam lingkungan masyarakat sehingga siswa pun akan termotivasi agar dapat memperbaiki status sosial ekonomi orang tuanya dengan cara bekerja.

3. Hubungan antara kemampuan prakerin dan status sosial ekonomi orang tua dengan motivasi bekerja siswa kelas XII TIPTL di SMKN5 Jakarta

Berdasarkan hasil perhitungan yang telah dikemukakan di atas, diketahui hasil regresi berganda yaitu sebesar $\hat{\mathrm{Y}}=36,881+0,402 \mathrm{X}_{1}+$ $0,370 X_{2}$. Persamaan tersebut memiliki arti nilai, konstanta (a) sebesar 36,881 yang berarti jika kemampuan prakerin dan status sosial ekonomi mengalami kenaikan/penurunan, maka motivasi berkerja positif sebesar 36,881 . Nilai koefisien regresi variabel $\mathrm{X}_{1}$ sebesar 0,402 , yang berarti jika status sosial ekonomi orang tua tetap dan kemampuan prakerin ditingkatkan 1, maka motivasi bekerja akan meningkat sebesar 0,402. Nilai koefisien regresi variabel $\mathrm{X}_{2}$ sebesar 0,370 , yang berarti jika kemampuan prakerin tetap dan status sosial ekonomi orang tua ditingkatkan 1, maka motivasi bekerja akan meningkat sebesar 0,370 . 
Berdasarkan analisis bahwa koefisien korelasi antara kemampuan prakerin dan status sosial ekonomi orang tua dengan motivasi bekerja dimana $r_{\mathrm{y} 1}=0,758$ dan $r_{\text {tabel }}=0,239$ maka $\mathrm{r}_{\text {hitung }}>\mathrm{r}_{\text {tabel }}$ yang berarti terdapat adanya hubungan positif, sertaF $F_{\text {hitung }}=43,96$ dan $\mathrm{F}_{\text {tabel }}=$ 3,14 maka $F_{\text {hitung }}>F_{\text {tabel, }}$ yang berarti $F_{h}>F_{t}=$ Ho ditolak : koefisien korelasi ganda signifikan dan terdapat hubungan yang signifikan antaravariabel Kemampuan Prakerin $\left(\mathrm{X}_{1}\right)$ danStatus Sosial Ekonomi Orang Tua $\left(\mathrm{X}_{2}\right)$ dengan variabel Motivasi Bekerja(Y). Salain itu dari perhitungan diperoleh koefisien determinasi sebesar $57,5 \%$, sehingga dapat disimpulkan bawha variabel motivasi bekerja (Y) ditentukan sebesar $57,5 \%$ oleh variabel kemampuan prakerin $\left(\mathrm{X}_{2}\right)$ dan status sosial ekonomi orang tua $\left(\mathrm{X}_{2}\right)$.

\section{KESIMPULAN DAN SARAN}

\section{Kesimpulan}

1. Terdapat hubungan yang positif dan signifikanantara kemampuan prakerin dan motivasi bekerja siswa kelas XII TIPTL di SMKN5 Jakarta. Karena berdasarkan hasilperhitungan hipotesis penelitian menunjukan $r_{\text {hitung }}=0,611$ dan $r_{\text {tabel }}=0,239$ yang berarti $r_{\text {hitung }}>r_{\text {tabel }}$. Berdasarkan data-data tersebut, dapat disimpulkan bahwa terdapat hubungan antara kemampuan prakerin yang berkonstribusi sebesar $37,35 \%$ pada motivasi kerja siswa kelas XII TIPTL di SMKN5 Jakarta.

2. Terdapat hubungan yang positif dan signifikan antara status sosial ekonomi orang tua dengan motivasi bekerja siswa kelas XII TIPTL di SMKN5 Jakarta. Karena berdasarkan hasil perhitungan hipotesis penelitian menunjukan $r_{\text {hitung }}=0,720$ dan $r_{\text {tabel }}=0,239$ yang berarti $\mathrm{r}_{\text {hitung }}>\mathrm{r}_{\text {tabel. }}$.Berdasarkan data-data tersebut, dapat disimpulkan bahwa terdapat hubungan antara status sosial ekonomi orang tua yang berkonstribusi sebesar $51,81 \%$ pada motivasi kerjasiswa kelas XII TIPTL di SMKN5 Jakarta.

3. Terdapat hubungan yang positif dan signifikan antara kemampuan prakerin dan status sosial ekonomi orang tua dengan motivasi bekerja siswa kelas XII TIPTL di SMKN5 Jakarta. Dikarenakan hasil dari parhitungan uji signifikan korelasi gandadinyatakan $F_{\text {hitung }}=43,96$ dan $\quad F_{\text {tabel }}=3,14$ sehingga $F_{\text {hitung }}>F_{\text {tabel. }}$. Berdasarkan data-data tersebut, dapat disimpulkan bahwa terdapat hubungan antara kemampuan prakerin dan status sosial ekonomi orang tua dan motivasi kerja siswa kelas XII TIPTL di SMKN5 Jakarta sebesar $57,5 \%$.

\section{Saran}

1. Sekolah agar bisa lebih meningkatkan kegiatan teori maupun praktek untuk pembekalan siswa sebelum prakerin. Agar siswa pun lebih paham ketika pelaksanaan prakerin jika materi teori ataupun praktik tentang apa yang dikerjakan di dalam prakerin telah sering dilatihkan disekolah.

2. Setelah siswa melaksanakan prakerin pihak sekolah juga mengadakan test ulang terkait kemampuan prakerin apa saja yang telah dimiliki siswa.

\section{DAFTAR PUSTAKA}

Adi, Rianto. (2010), Metodologi Penelitian Sosial dan Hukum. Jakarta : Granit

Aidar, John. (1994), Menjadi Pemimpin yang Efektif, Jakarta : Gramedia.

Anoraga, Pandji. (2005). Manajemen Bisnis. Jakarta : Rineka Cipta.

Arikunto, Suharsimi. (2013). Prosedur Penelitian. Jakarta : Rineka Citra.

As'ad, Mohammad. (2004). Psikologi Industri. Yogyakarta : Liberty.

Bukhari, Zainun. (2004). Manajemen dan Motivasi. Jakarta : Balai Aksara.

Chourmain, Iman (1998). Pengatar Ilmu Ekonomi.Jakarta : Departemen Pendidikan dan Kebudayaan.

Devy Ika Puspitasari, 5301406003 (2010) Studi Eksplorasi Tentang Pola Kerjasama Praktik Kerja Industri Jurusan Rekayasa Perangkat Lunak SMK Negeri 1 Tengaran Kabupaten Semarang, Provinsi Jawa Tengah. Under Graduates thesis, Universitas Negeri Semarang.

Dini Arini, 06505241019 (2010) Pengaruh Prestasi Praktik Kerja Industri dan Pengetahuan Kewirausahaan terhadap minat berwirausaha siswa kelas 3 teknik Bangunan SMK Negeri 2 Pengasiha Tahun 2010/2011, Universitas Negeri Yogyakarta 
Firmansyah Aditya, 088554134 (2013) Analisis Pelaksanaan Praktik Kerja Industri (Prakerin) pada Program Keahlian Administrasi Perkantoran Kelas XI SMK Negeri 4 Surabaya. Universitas Negeri Surabaya

Fredi Prima Sakti (2014) yang berjudul "Pengaruh Penguasaan Kompetensi Keahlian dan Informasi Dunia Kerja Terhadap Minat Bekerja Siswa Kelas XI Program Keahlian Teknik Instalasi Tenaga Listrik di SMKN 2 Yogyakarta" Fakultas Teknik Universitas Negeri Yogyakarta

Gie, Liang (1992), Cara Bekerja Efisien.Yogyakarta : Liberty.

Hasan, Iqbal. (2004). Analisis Data Penelitian dengan Statistik. Jakarta : Bumi Aksara.

Hasibuan, Malayu S.P. (2003). Manajemen Sumber Daya Manusia. Jakarta : Bumi Aksara.

Manribu, Moh Thayeb.(1998). Pengantar Bimbingan dan Konseling Karir. Jakarta: Depdikbud.

Moeheriono. (2010), Pengukuran Kinerja Berbasis Kompetensi. Jakarta : Ghalia Indonesia.

Nasution. (2004). Sosiologi Pendidikan. Jakarta:Bumi Aksara.

Nolker, H. danSchoenfeld, E. (1988). Pendidikan Kejuruan (Pengajaran, Kurikulum, Dan Perencanaan). Jakarta : Gramedia

Noor, Juliansyah. (2010). Metodologi Penelitian. Jakarta:Kencana.

Riduwan. (2007). Rumus dan Data dalam Analisis Statistika. Bandung:Alfabeta

Sardirman. (2006). Interaksi \& Motivasi Belajar Mengajar. Jakarta : PT Raja Grafindo Persada.

Sartika Partomo, Tiktik dan Soejoedono, Abd. Rachman (2002), Ekonomi Skala Kecil / Menengah dan Koperasi, Jakarta : Ghalia Indonesia.

Siagian, Sondang P. (2004), Teori Motivasi dan Aplikasinya, Jakarta : PT Asdi Mahasatya.

Siregar,Eveline dan Nara, Hartini (2010), Teori Belajar dan Pembelajaran, Jakarta : Ghalia Indonesia.

SMK Negeri 5 Jakarta (2016), Jurnal Praktik Kerja. Jakarta : TIM prakerin SMK Negeri 5 Jakarta.

Sugiyono, (2010). Metode Penelitian Kuantitatif Kualitatif dan $R \& D$. Bandung : Alfabeta.
Sugiyono, (2011). Metode Penelitian Kuantitatif Kualitatif dan $R \& D$. Bandung : Alfabeta.

Sukestiarno. (2014). Statistik Dasar. Yogyakarta : ANDI.

Todaro, Michael P. (2000). Pembangunan Ekonomi di Dunia Ketiga. Jakarta : Erlangga.

Uno,Hamzah B. (2007), Teori Motivasi dan Pengukurannya Analisis di Bidang Pendidikan, Jakarta : PT Bumi Aksara.

Wena, Made. (1996). Pemanfaatan Industri sebagai Sumber Belajar dalam PSG. Jakarta:Dikbud.

Zulkifli, (1998). Psikologi Belajar. Jakarta : FIP IKIP 